\title{
Ball milling pretreatment of oil palm biomass for enhancing enzymatic hydrolysis
}

\begin{abstract}
Oil palm biomass, namely empty fruit bunch and frond fiber, were pretreated using a planetary ball mill. Particle sizes and crystallinity index values of the oil palm biomass were significantly reduced with extended ball mill processing time. The treatment efficiency was evaluated by the generation of glucose, xylose, and total sugar conversion yields from the pretreatment process compared to the amount of sugars from raw materials. Glucose and xylose contents were determined using high-performance liquid chromatography. An increasing trend in glucose and xylose yield as well as total sugar conversion yield was observed with decreasing particle size and crystallinity index. Oil palm frond fiber exhibited the best material yields using ball milling pretreatment with generated glucose, xylose, and total sugar conversion yields of 87.0, 81.6, and $85.4 \%$, respectively. In contrast, oil palm empty fruit bunch afforded glucose and xylose of 70.0 and $82.3 \%$, respectively. The results obtained in this study showed that ball mill-treated oil palm biomass is a suitable pretreatment method for high conversion of glucose and xylose.
\end{abstract}

Keyword: Ball milling; Enzymatic hydrolysis; Oil palm empty fruit bunch; Oil palm frond fiber; Pretreatment 